\title{
Study of the Method for Single Missile Storage Life Evaluation Based on Test Data
}

\author{
XI Wen Jun ${ }^{1, a}$, WANG Wen Shuang ${ }^{1, b}$ \\ ${ }^{1}$ Naval Aeronautical And Astronautical University, ShanDong YanTai, China \\ alinn836001@sina.cn, b743122852@qq.com
}

Keywords: missile; storage life evaluation; mobile standard deviation

\begin{abstract}
To investigate the storage life evaluation method for single missile. The regular status test data was statistically analyzed, the variation of the test data was determined. The stability of the test data was discussed through the introduction of the "Mobile Standard Deviation (MSD)"conception. The MSD, which is one of the most important characteristic parameters of the missile, was forecasted with the application polynomial least-squares, the missile storage stability level was calculated, and the single missile storage life evaluation model was established. Through the case analysis, the rationality of the evaluation model was validated.
\end{abstract}

\section{Introduction}

Missile storage life evaluation is the key technology concerning the missile "six performance" index construction. At present, the design characteristics of the missile uses the conservative life evaluation method on the life index generally, to ensure that the missile run reliably and safely during the storage and use period ${ }^{[1]}$. Missile life evaluation can get accurate missile storage life evaluation value, not only can exert the potential missile life, avoid premature retirement, give full play to resource efficiency, but also can avoid the blindness prolonging life which will cause unexpected pitfalls. This paper lead into mobile standard deviation in the analysis of characteristic parameters of the key components of the service life, study on the degradation law of missile storage stability, establish the storage life evaluation model test data based on a single missile, and carries on the example analysis, and provides a technical support maintenance decision for the missile troops.

\section{Missile Test Data and the Choice of Characteristic Parameters of Key Components}

By comparison, use the state monitoring data method for a single missile storage life evaluation. The army will regularly test each missile, the test data is the status data of missile easy access, the measured data can be used to characterize the state of each missile. Therefore, storage life evaluation use the missile test data to analysis and calculate [2].

Now take the automated test system for missile test of a certain type of missile, the main testing items amounts to 108 items of test parameters. The test results of analog test parameters are characterized by a specific numerical thresholds within, can study on the variation law of parameters based on over the years the test data of analog test parameters, degenerate cases drawn missile state, so as to realize the storage life of missile evaluation. So the storage life evaluation of missile, only need to carry on the research of test parameters of analog quantity.

\section{The Establishment and Check of Evaluation Model}

A. Mobile standard deviation

The concept of standard deviation, provided a group of sample data $X=\left\{x_{1}, x_{2}, x_{3}, \ldots x_{n}\right\}$, then $\delta=\sqrt{\frac{1}{n} \sum_{i=1}^{n}\left(x_{i}-\bar{x}\right)^{2}}$ 
In the magnitude: $\delta$ is the sample standard deviation of data; $\mathrm{n}$ is the number of samples; $\bar{x}$ is the mean of the sample data.

The test data of standard deviation is a index to measure the stability of test data. Numerical value of standard deviation larger, represents test data more away from a standard value. On the contrary, the numerical value standard deviation smaller represents the test data more stable. As a result of the analysis of test data of standard deviation can only analyze the stability conditions of the test data, and can not analyze the development trend of the stability of the test data, so lead into the concept of mobile standard deviation. Provided a group of sample data $X=\left\{x_{1}, x_{2}, x_{3}, \ldots x_{n}\right\}$, then mobile standard deviation of the sample data is

$$
\delta_{\imath}=\sqrt{\frac{\sum_{i=1}^{m}\left(x_{i+j+1}-\tilde{x}\right)^{2}}{m}},(i=1,2,3, \ldots n-m)
$$

In the magnitude: $\delta_{1}$ is the mobile standard deviation of the sample data; $\mathrm{m}$ is the mobile step; $\tilde{x}$ is the mean of the sample data.

Mobile standard deviation can reflect changes in the test data compared to the standard value trend and key components of the storage stability of missile.

B.Curve fitting obtain the valuation model

Get the mobile standard deviation time series to polynomial fit ${ }^{[4-5]}$, obtain the storage life evaluation model of missile key components. Polynomial fitting method is: the assumption that the given data points $\left(x_{i}, y_{i}\right)(i=1,2,3, \ldots n-m), \Phi$ is function class that all times not exceeding polynomial form, solve $D_{n}(x)=\sum_{k=0}^{n} a_{k} x^{b} \in \Phi$ 。

$$
\mathrm{I}=\sum_{\mathrm{i}=1}^{m}\left[D_{n}(x)-y_{i}\right]^{2}=\sum_{i=0}^{m}\left(\sum_{k=}^{n} i_{k} x^{k}-y_{i}\right)^{2}
$$

Make I the minimum value, when fitting function is a polynomial, call it polynomial fitting, $\mathrm{P}_{\mathrm{n}}(x)$ which fits magnitude (2) is called least squares fitting polynomial. Specially, it is called linear fitting or linear fitting when $n=1 . \mathrm{I}=\sum_{i=0}^{m}\left(\sum_{k=}^{n} i_{k} x^{k}-y_{i}\right)^{2}$ is multi function of $a_{0}, a_{1}, \ldots a_{n}$, the above problems is to solve the extreme value of $I=I\left(a_{0}, a_{1}, \ldots a_{n}\right)$. Based on the necessary condition for the extreme value of multivariate function, obtain:

$$
\begin{aligned}
& \frac{\partial I}{\partial a_{i}}=2 \sum_{i=0}^{m}\left(\sum_{k=0}^{n} i_{k} x^{k}-y_{i}\right) x_{i}^{j}=0,(j=0,1, \ldots, n) \\
& \sum_{k=0}^{n}\left(\sum_{i=0}^{m} x_{i}^{i+k}\right) a_{k}=\sum_{i=0}^{n} i_{i}^{j} y_{i},(j=0,1, \ldots n)
\end{aligned}
$$

Magnitude (4) is linear equation group of $a_{0}, a_{1}, \ldots a_{n}$, with the matrix representation for:

$$
\left(\begin{array}{ccc}
m+1 & \cdots & \sum_{i=0}^{m} x_{i}^{n} \\
\vdots & \ddots & \vdots \\
\sum_{i=0}^{m} x_{i}^{n} & \cdots & \sum_{i=0}^{m} x_{i}^{2 n}
\end{array}\right)\left(\begin{array}{l}
a_{0} \\
a_{1} \\
\vdots \\
a_{n}
\end{array}\right)=\left(\begin{array}{l}
\sum_{i=0}^{m} y_{i} \\
\sum_{i=0}^{m} x_{i} y_{i} \\
\vdots \\
\sum_{i=0}^{m} x_{i}^{n} y_{i}
\end{array}\right)
$$

Magnitude (4) or(5) is called normal equations system or normal equations.

The coefficient matrix of magnitude (5) is a symmetric positive definite matrix, therefore, exist uniqueness of solution, solve $a_{k}(k=0,1, \ldots n)$, then

$$
D_{n}(x)=\sum_{k=0}^{n} a_{k} x^{k}
$$


$P_{n}(x)$ in magnitude (6) meets magnitude (6), $P_{n}(x)$ is the request fitting polynomial, $\sum_{\mathrm{i}=0}^{m}\left[D_{n}\left(x_{i}\right)-y_{i}\right]^{2}$ is the square error of the least square curve fitting polynomial $\mathrm{P}_{\mathrm{n}}(x)$,

$$
\|r\|_{2}^{2}=\sum_{\mathrm{i}=0}^{m} y_{i}^{2}-\sum_{k=0}^{n} a_{k}\left(\sum_{i=0}^{m} x_{i}^{k} y_{i}\right)
$$

Storage life evaluation model is $\mathrm{P}_{\mathrm{n}}(x)$, mobile standard when the key components of regular testing parameter difference evaluation value exceeds the requirements of test parameters of the component technology, the component can be considered to life.

\section{The Example Analysis}

To determine the weak link of the missile through research and analysis, use the test parameters to analyze the weak link of the missile storage life ${ }^{[6-7]}$. The key components of a certain type of missile impact of storage life for power supply, the magnetron, gyroscope, altimeter. Technical standard of each parameter were $(24+3) \mathrm{V},(13.5+2.5) \mathrm{V},(5+0.25) \mathrm{V}$, $(30+3) \mathrm{M}$. A test playing 5 years increased regular test data density is shown in table 1 .

Table 1 Missile key components characteristics test data Table 2 Mobile standard deviation of Missile key components

characteristics test data

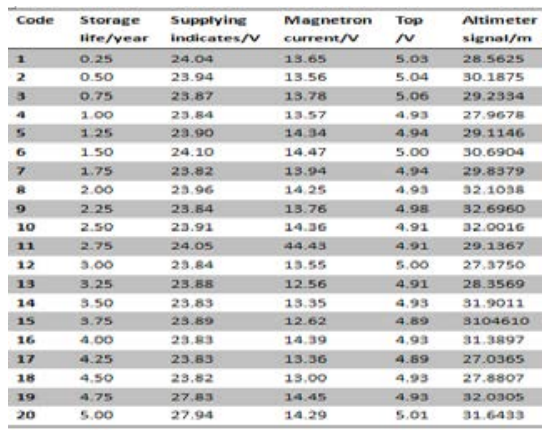

\begin{tabular}{|c|c|c|c|c|c|}
\hline Code & $\begin{array}{l}\text { Storage } \\
\text { life/year }\end{array}$ & $\begin{array}{l}\text { Supplying } \\
\text { indicates } / \mathrm{V}\end{array}$ & $\begin{array}{l}\text { Magnetron } \\
\text { current/V }\end{array}$ & Top $/ V$ & $\begin{array}{l}\text { Altimeter } \\
\text { signal/m }\end{array}$ \\
\hline 1 & 1.25 & 0.1074 & 0.1496 & 0.0540 & 1.2331 \\
\hline 2 & 1.50 & 0.1150 & 0.3987 & 0.0523 & 1.0967 \\
\hline 3 & 1.75 & 0.1378 & 0.5886 & 0.0560 & 1.0690 \\
\hline 4 & 2.00 & 0.1262 & 0.6202 & 0.0583 & 1.4032 \\
\hline 5 & 2.25 & 0.1263 & 0.6939 & 0.0500 & 4.6114 \\
\hline 6 & 2.50 & 0.1274 & 0.7029 & 0.0586 & 1.8003 \\
\hline 7 & 2.75 & 0.1158 & 0.7077 & 0.0703 & 1.8152 \\
\hline 8 & 3.00 & 0.1126 & 0.6969 & 0.0764 & 2.1604 \\
\hline 9 & 3.25 & 0.1235 & 0.6689 & 0.0815 & 2.0351 \\
\hline 10 & 3.50 & 0.1261 & 0.7153 & 0.0775 & 1.8486 \\
\hline 11 & 3.75 & 0.1292 & 0.7090 & 0.0826 & 1.6285 \\
\hline 12 & 4.00 & 0.1483 & 0.7138 & 0.0853 & 1.6997 \\
\hline 13 & 4.25 & 0.1505 & 0.7036 & 0.0835 & 1.7992 \\
\hline 14 & 4.50 & 0.1620 & 0.7379 & 0.0772 & 1.9423 \\
\hline
\end{tabular}

Take the regular test data from table 1 into the magnitude (1), take the mobile step, get the mobile standard deviation of key components, see table 2 .

The mobile standard of the key components of the missile obtained from table 2 through magnitude (6), (7) to fitting calculate.

1) Storage life evaluation model of power is:

$\mathrm{P}(x)=0.0014 \bullet x^{3}-0.0081 \bullet x^{2}+0.0196 \bullet x+0.1028$

Square error of model $=1.191361 \times 10^{-3}$

2) Storage life evaluation model for magnetron is:

$$
\mathrm{P}(x)_{2}=0.0602 \bullet x^{3}-0.6235 \bullet x^{2}+2.0907 \bullet x-1.5547
$$

Square error of model $=1.574279 \times 10^{-2}$

3 ) Storage life evaluation model for gyroscope is:

$$
\mathrm{P}(x)_{3}=0.0012 \bullet x^{4}-0.0164 \bullet x^{3}+0.0801 \bullet x^{2}-0.1514 \bullet x+0.1485
$$

Square error of model $=2.356779279 \times 10^{-4}$

4) Altimeter storage life evaluation model is:

$$
\mathrm{P}(x)_{4}=0.1028 \bullet x^{4}-1.2294 \bullet x^{3}+5.0587 e \bullet x^{2}-8.0675 x+5.4860
$$

Square error of model $=2.191728 \times 10^{-1}$

The key components of known missile test parameter threshold respectively: 1.6082, 1.5402, $0.2715,5.3675$, assessment of modulus value reaches a threshold value is the key components of the storage life. The storage life of key components of the missile life power, magnetron, gyroscope, altimeter are respectively 12, 6, 7, 5 years. 


\section{Conclusion}

Through the statistics and analysis of test data of missile state regular data, determine the change rule of the test data, select the characterization of pilot plan analysis, determine the change rule of the test data, choose the characteristic parameters which characterize life of missile key components, analyze the characteristic parameters which characterize life of missile key components and lead into the concept of mobile standard deviation, establish storage life the evaluation model of single missile, and analyze the example, verify the rationality of the evaluation model, the method can provide a reference for missile security order prolong life and condition based repair.

\section{References}

[1] ZHU Bing-yu, ZHAN Xue-min, ZHANG Xing-you. Technology Overview of Foreign Missile[J]. Winged Missiles, 2009 (10) : 23-25.

[2] WANG Chun-hui, LI Zhong-dong, ZHANG Sheng-peng.Storage Life Analysis of Aircraft Missile[J]. Equipment Environmental Engineering, 2011, 8 (4) : 68-72.

[3] SUN Lin. Study of Quality Control of Product Process Based on Standard Deviation $\sigma$ prediction with WLS-SVM[J].Journal of Hefei University of Technology, 2013, 36 (2) : 231-235.

[4] HUANG Xu-lan, BAI Yan-ping, LI Shuo, et al. Some Properties about Cartesian Product on Set[J]. Journal of Taiyuan Normal University, 2011, 10 (2) : 7-11.

[5] ZHANG Liang, ZHANG Xin-ping. Eliminating Intolerble Errors Contained in Flight Research Data[J]. Journal of Northwestern Polytechnical University, 2011, 29 (4) : 637-639. 